
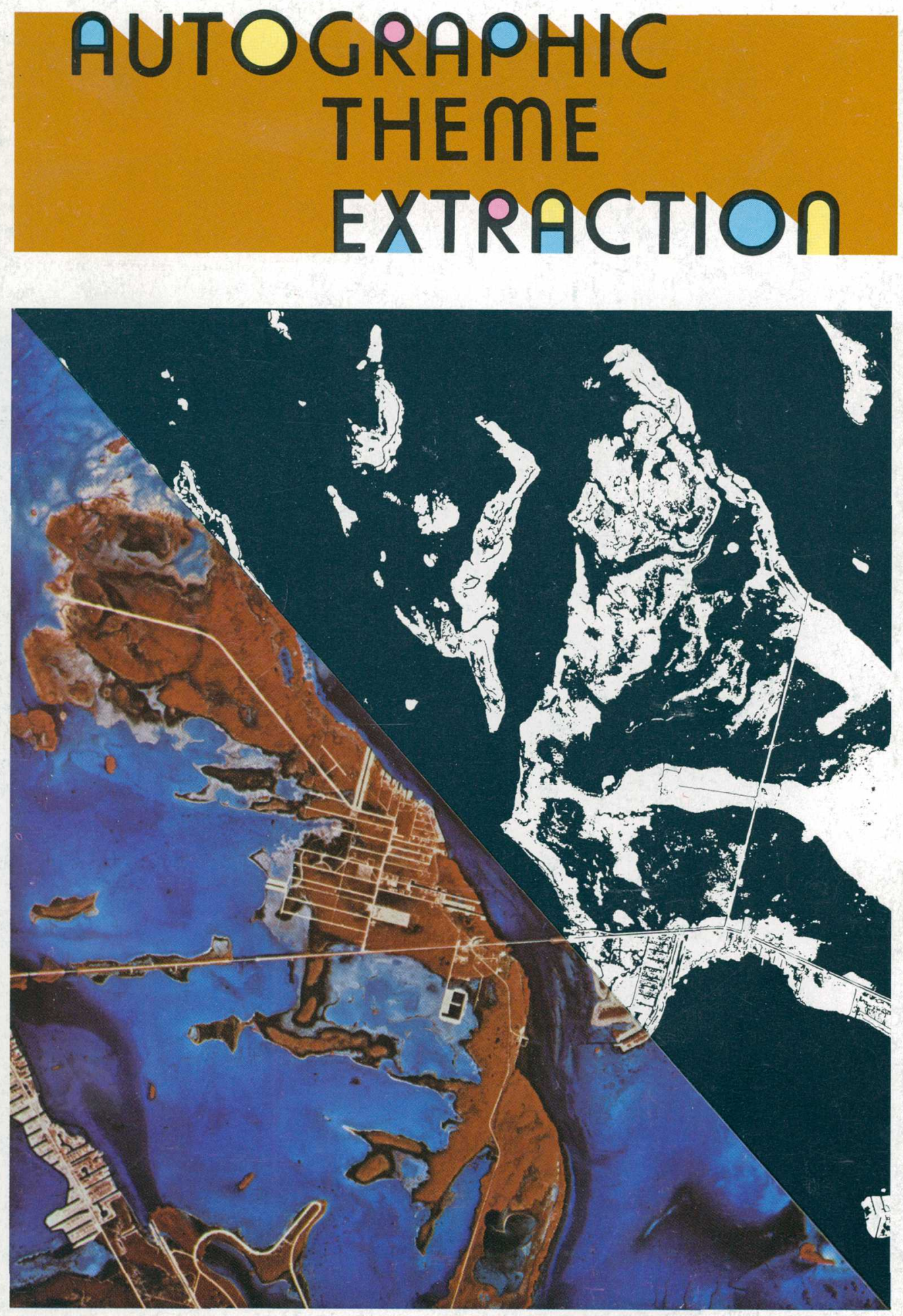

U.S. DEPARTMENT OF THE INTERIOR/GEOLOGICAL SURVEY 

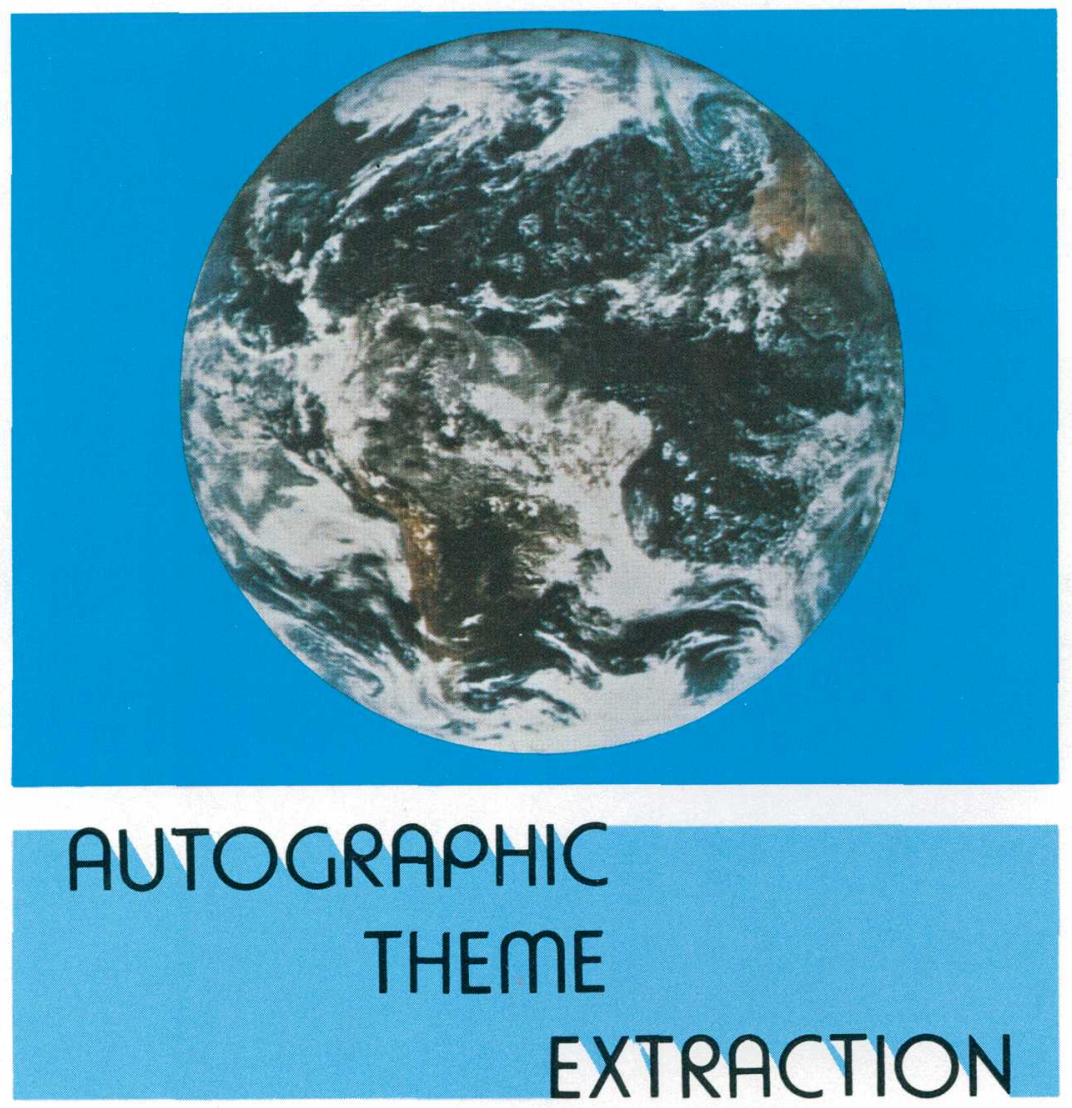

What is it?

Remote-sensor images, including aerial and space photographs, are generally recorded on film, where the differences in density create the image of the scene. With panchromatic and multiband systems the density differences are recorded in shades of gray. On color or color infrared film, with the emulsion containing dyes sensitive to different wavelengths, a color image is created by a combination of color densities. The colors, however, can be separated by filtering or other techniques, and the color image reduced to monochromatic images in which each of the separated bands is recorded as a function of the gray scale. Certain basic phenomena or themes on the Earth's surface, under appropriate conditions, are recorded in a unique 
and distinct density or combination of densities, for example:

- Open water

- Snow and ice

- Infrared-reflective vegetation

- Massed works of man

The process of automatically isolating the image of one or more of these themes from the remainder of the image is here referred to as Autographic Theme Extraction. The phrase implies photographic and/or digital processing of images as opposed to human interpretation, which is fundamental to most thematic mapping. The product of this process is a binary (yes/ no) representation of a subject or theme that has been isolated from an image and yet retains the precise geometry and resolution of the original image of the theme.

The illustrations in this leaflet are experimental samples of the type of products expected from the Autographic Theme Extraction system now being developed by the Topographic Division, U.S. Geological Survey, in support of the Department of the Interior's Earth Resources Observation Systems (EROS) Program. These samples were derived by photographic density slicing of images involving one to three spectral bands. The reliability and quality of the products are expected to be improved by the process of density correction, which was not applied to the illustrated samples.

\section{How is it done?}

Density correction to normalize each photographic image is the first major step in the theme extraction process. In this step, each image is sampled for nonuniform image density of known similar features, such as open water. The density samples are computerprocessed to derive a correction function for the complete image. This function is defined by a series of mathematical terms, which are used to generate a density filter by digital-to-analog conversion. When placed over the original image, the filter normalizes the density across the image as though the scene were evenly illuminated. 
The second major processing step involves multichannel image analysis. The associated hardware permits spectrally variant images of a single scene to be scanned and stored in geometric register on a video disk recorder. Any combination of the stored images can be electronically processed for display on a television monitor. A trained operator can then determine and document the spectral band combinations and photographic processing parameters required to best isolate the theme from the original image.

The final step is theme extraction by photomechanical processing of images according to the information derived in the previous steps. As an alternative, digital processing could be used for isolating and printing the thematic extractions, but the photographic process is now considered to be more efficient and superior for retaining the resolution and geometry of the original theme image, both of which are required for cartographic products.

The format of the isolated themes will be either that of the image frame or of a standard quadrangle. In either format, the Universal Transverse Mercator (UTM) grid and latitude and longitude indicators will be added to the products for precise earth referencing.

\section{Where and when?}

The Autographic Theme Extraction system is scheduled for installation at the EROS Data Center in Sioux Falls, South Dakota, by 1973. The return beam vidicon cameras and multispectral scanners of the Earth Resources Technology Satellite will provide the basic inputs to the system, although it can also be used for isolating themes from aerial and space photographs.

Inquiries and comments concerning Autographic Theme Extraction should be directed to the U.S. Geological Survey, Cartography Coordinator, EROS Program, Washington, D.C. 20242.

(from material supplied by D. Edson and A. Colvocoresses)

The photographs on the following pages are by the National Aeronautics and Space Adminisration Agency (NASA): the extractions are by Philco-Ford, Inc. under contract to the U.S. Geological Survey. 

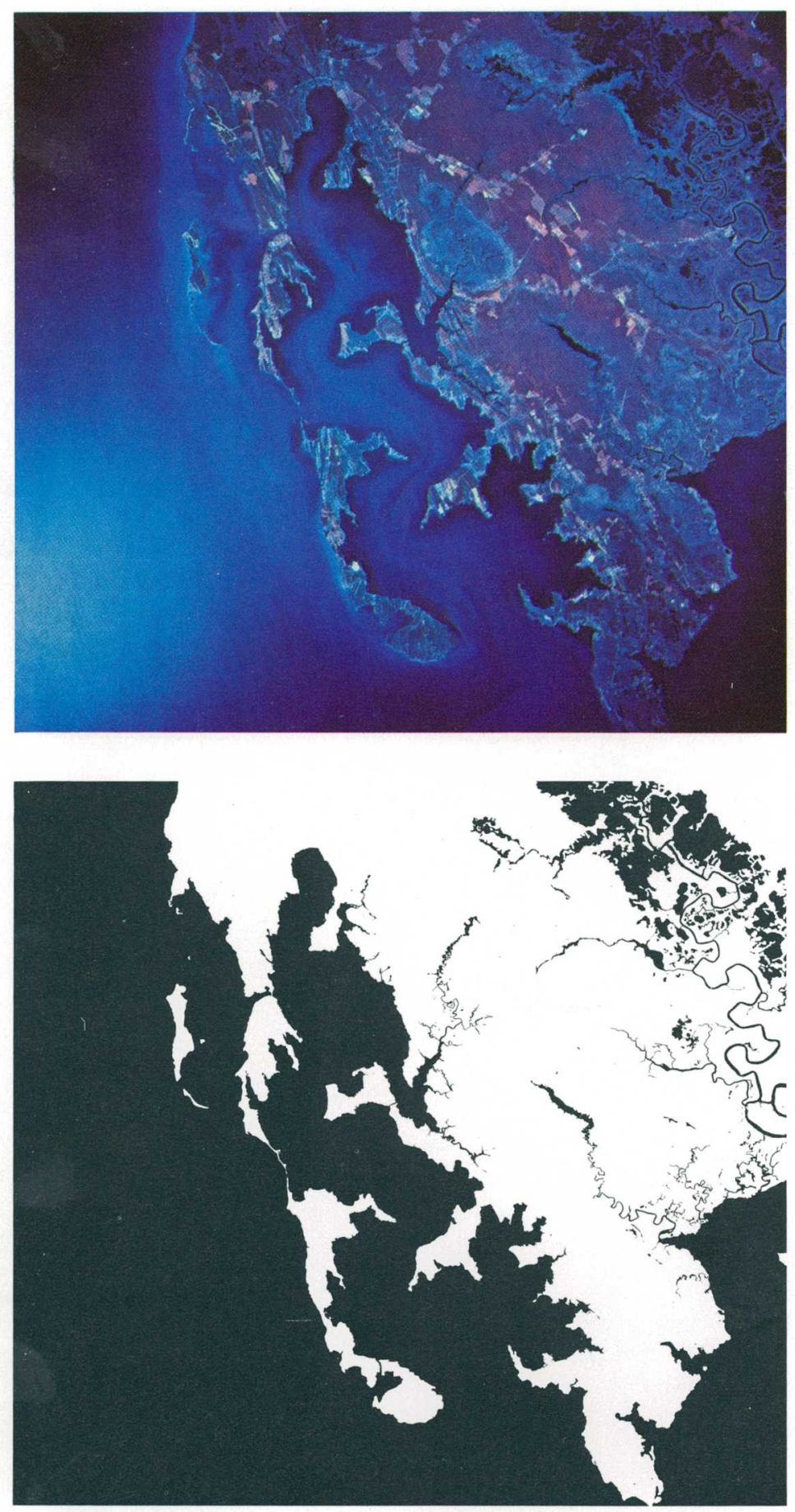

Color infrared photograph (at top) taken at 60,000 feet with 6-inch mapping camera. Extraction of water, Chesapeake Bay area (at bottom). 

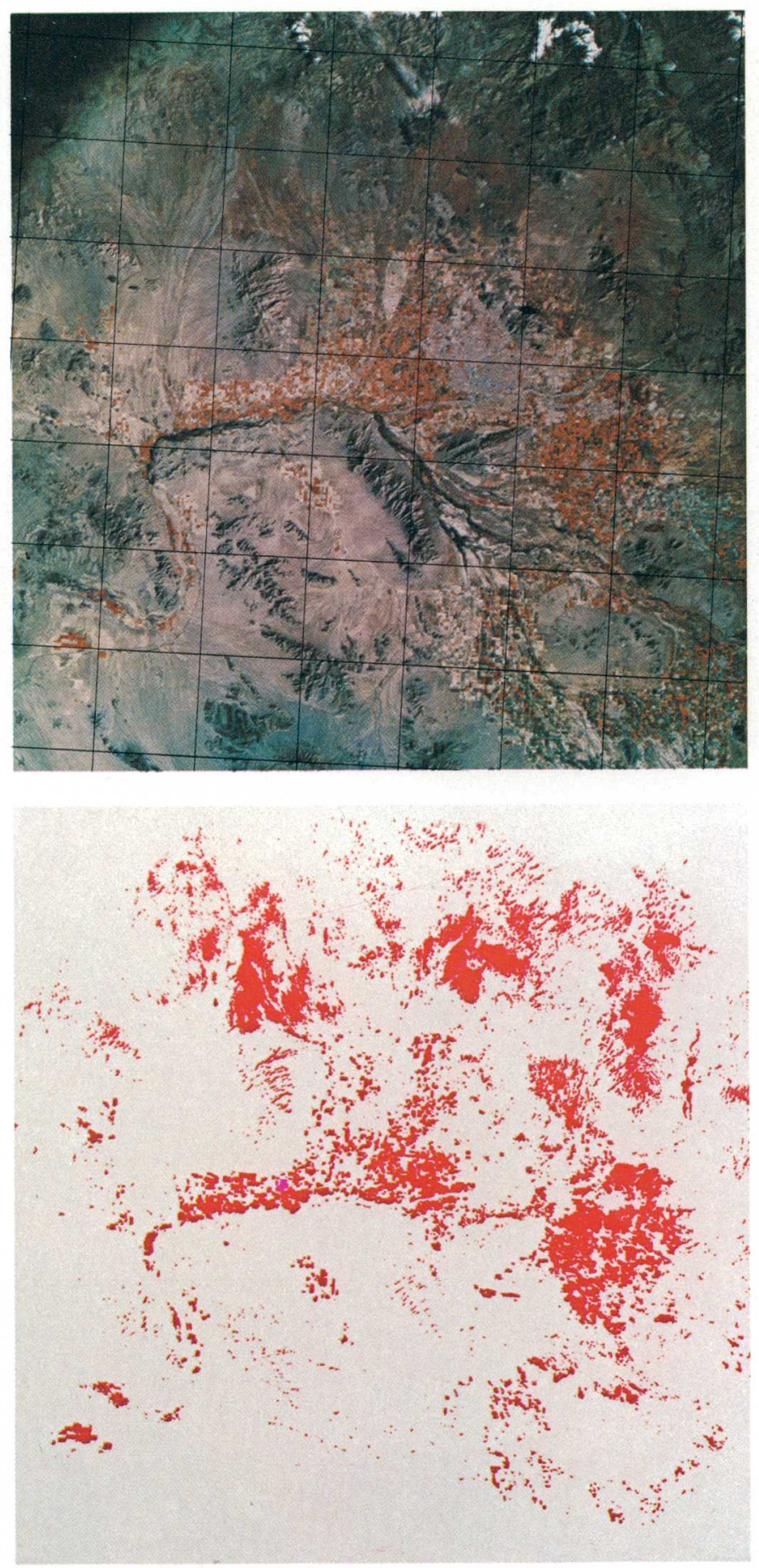

Color infrared photograph ( at top) taken at 127 nautical miles with Hasselblad camera (Apollo 9). Extraction of IR-reflective vegetation, Phoenix, Arizona area (at bottom). 

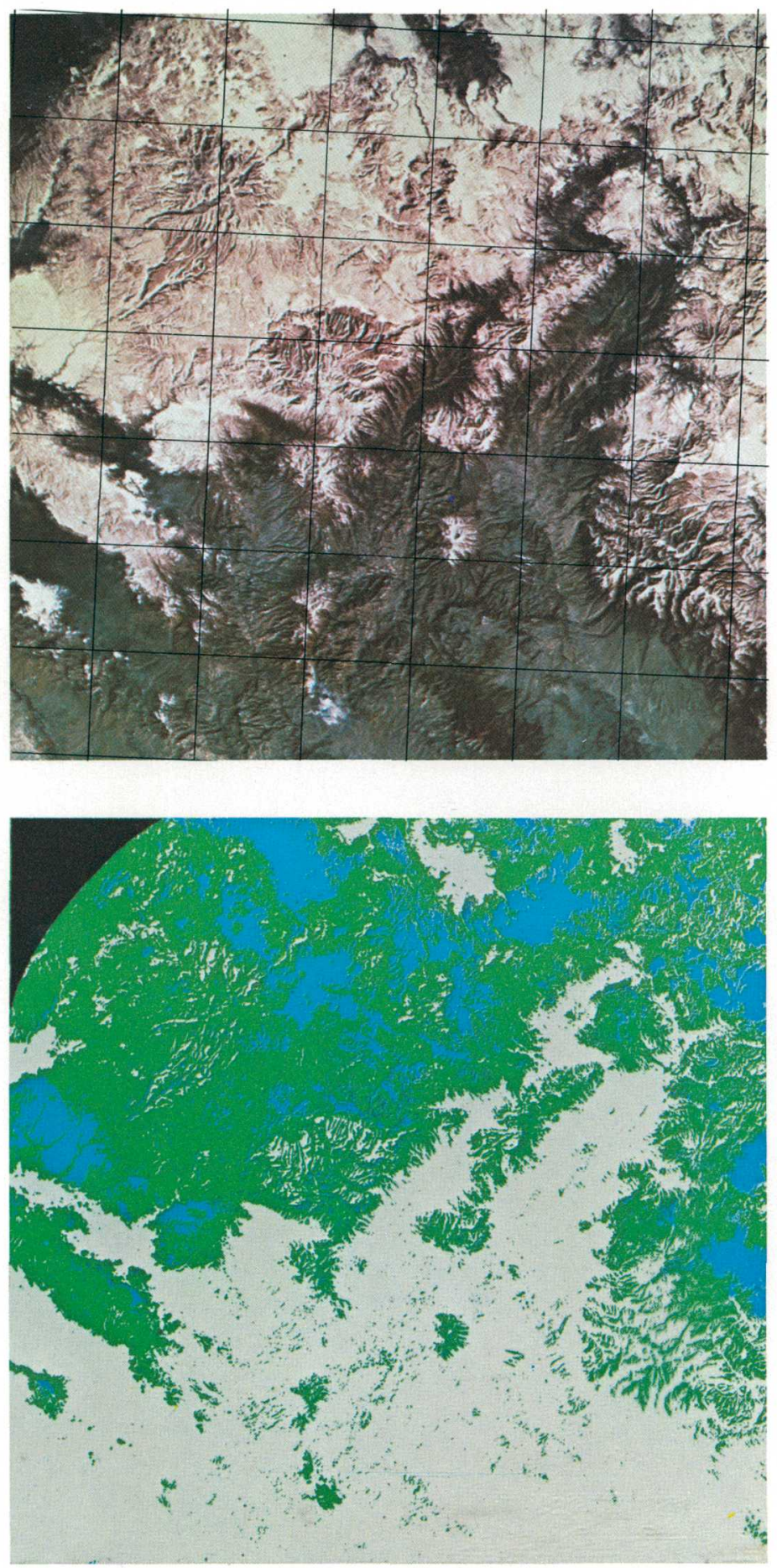

Coior infrared photograph (at top) of Arizona area (Apollo 9). Extraction of snow: light snow, green; deep snow, blue (at bottom). 
As the Nation's principal conservation agency, the Department of the Interior has basic responsibilities for water, fish, wildlife, mineral, land, park, and recreational resources. Indian and Territorial affairs are other major concerns of America's "Department of Natural Resources."

The Department works to assure the wisest choice in managing all our resources so each will make its full contribution to a better United Statesnow and in the future. 